\title{
Phaeochromocytoma in pregnancy
}

\author{
Harshika Chathurangi Hannadige ${ }^{1 *}$, Marie Fernando ${ }^{2}$ \\ Registrar in Anaesthetics ${ }^{1 *}$, Consultant Anaesthetist ${ }^{2}$, National Hospital of Sri Lanka, \\ Colombo 10, Sri Lanka
}

\begin{abstract}
Phaeochromocytoma is a tumour of neuro-endocrine origin in the adrenal medulla. It is a rare cause of hypertension in pregnancy. Its prevalence in hypertensive patients is $0.2 \%$ and $0.002 \%$ in pregnancies. ${ }^{1}$
\end{abstract}

We report an anaesthetic experience of a combined caesarean section and surgical excision of a phaeochromocytoma in a patient who was $36+$ weeks pregnant.

Keywords: Phaeochromocytoma; pregnancy; caesarean section

\section{Introduction}

Phaeochromocytoma presents as paroxysmal episodes of headache, diaphoresis and hypertension. The "rule of 10 " (10\% tumours are malignant, $10 \%$ extra-adrenal, $10 \%$ bilateral, $10 \%$ familial and $10 \%$ occur in normotensive patients) has been challenged recently as there appears to be a higher proportion of tumours that are malignant (29\%), extra-adrenal (24\%) and/or familial $(32 \%){ }^{2}$

This tumour can also present with familial chromaffinomas which are inherited in an autosomal dominant manner such as multiple endocrine neoplasia type 2 and 3, neurofibromatosis and von Hippel Lindau disease. ${ }^{3,4}$

The clinical presentation is mainly due to effects of catecholamines. The commonest symptom is headache and the commonest sign is paroxysmal or sustained hypertension. The classic triad of symptoms include headache, sweating and palpitations. Early diagnosis and timely intervention reduce maternal and foetal death rates to less than $5 \%$ and $15 \%$, respectively. ${ }^{5}$

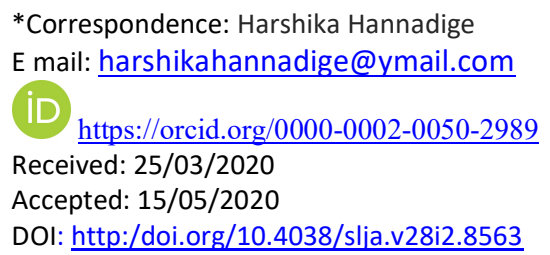

*Correspondence: Harshika Hannadige E mail: harshikahannadige@ymail.com

https://orcid.org/0000-0002-0050-2989 Received: 25/03/2020 Accepted: $15 / 05 / 2020$ DOI: http:/doi.org/10.4038/slja.v28i2.8563

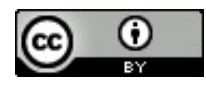

\section{Case description}

The patient was a 34 year old in her third pregnancy who was known to have type 1 neurofibromatosis. She was 34 weeks when she developed an episode of palpitations for which she was investigated. 12 lead ECG showed sinus rhythm with a resting rate of $80 / \mathrm{min}$ and she was waiting to undergo Holter monitoring. Ultrasound abdomen revealed a left sided suprarenal mass. Her blood pressure had been normal, and she revealed a 5 year history of intermittent headache, sweating and palpitations. She had given birth to two children by normal vaginal delivery 17 and 15 years ago respectively. She was referred to a tertiary care maternity hospital where multiple serum, urine and imaging tests were done.

Magnetic resonance imaging (MRI) revealed a left suprarenal gland tumour. Urinary Vanillylmandelic acid (VMA) was $33 \mathrm{ng} / \mathrm{dL}$ (normal range $1-13 \mathrm{ng} / \mathrm{dL}$ ) Urinary metanephrine was 5 times the normal $5.4 \mathrm{mg} / 24$ hours (normal range $<1.0 \mathrm{mg} / 24$ hours)

There was no family history of adrenal tumours.

Although normotensive, she was started on prazosin at 36+1 POA to expand her intravascular space and labetalol at $36+2$ POA. Elective caesarean section and adrenalectomy was planned at $36+3$ days of POA. One day before surgery she was admitted to the intensive care unit (ICU) and fluids were given to maintain a central venous pressure of $8-12 \mathrm{mmHg}$. Invasive blood pressure monitoring was commenced. Her blood sugar was normal. 
MR image of the suprarenal tumour

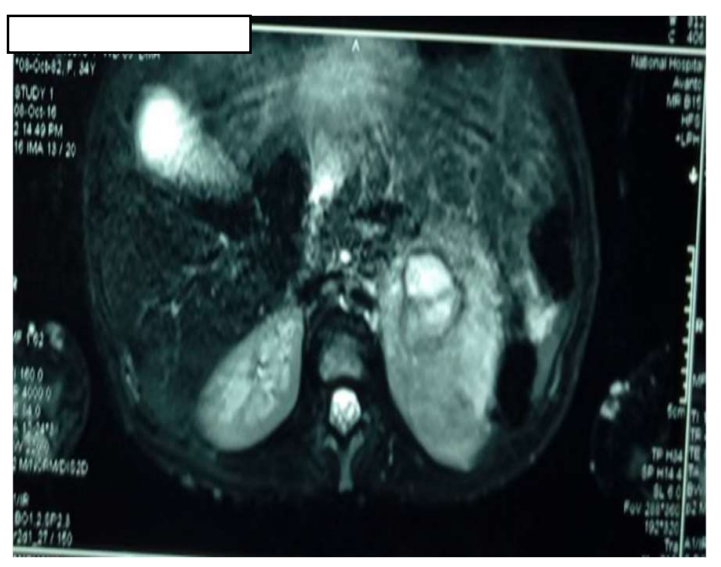

Preoperatively blood pressure was $100 / 60 \mathrm{mmHg}$. ECG was normal. She did not have orthostatic hypotension. Echocardiogram revealed normal biventricular function with an ejection fraction of $60 \%$. Airway assessment did not predict any difficulty. Antacid and prokinetic drugs were administered. Morning doses of prazosin and labetalol were not given as her blood pressure was $94 / 53 \mathrm{mmHg}$.

She was given sodium citrate at the operating theatre. Epidural insertion was not considered as spinal canal neurofibromata were not excluded by imaging. Invasive blood pressure, 5 lead ECG, pulse oximetry and central venous pressure were monitored. She was preoxygenated until an end tidal oxygen fraction of 0.9 achieved. A modified rapid sequence induction was done using magnesium sulphate $40 \mathrm{mg} / \mathrm{kg}$, remifentanil, precalculated dose of thiopentone sodium followed by suxamethonium. Trachea was intubated under cricoid pressure. Infusions of magnesium sulphate, vecuronium and remifentanil were started. Prophylactic antibiotics were administered prior to skin incision. Anaesthesia was maintained with isoflurane in 1:1 oxygen and nitrous oxide. Caesarean section commenced through a midline incision. A live baby was delivered. 5 unit bolus of syntocinon was slowly given followed by an infusion. Blood pressure remained stable.

Blood pressure started to rise with tumour handling. An esmolol infusion was started at $50 \mu \mathrm{g} / \mathrm{kg} / \mathrm{min}$. Few boluses of phentolamine 1$2 \mathrm{mg}$ were administered. Clamping of the adrenal vein caused a reduction in blood pressure to $80 / 40 \mathrm{mmHg}$. Magnesium sulphate and esmolol infusions were stopped and a noradrenaline infusion was started. Blood pressure was increased to $120 / 80 \mathrm{mmHg}$.

On completion of the surgery she was transferred to the intensive care unit (ICU) where she was extubated within a few hours. Her vital parameters and blood sugars were closely monitored. Noradrenaline infusion was tailed off.

\section{Discussion}

Phaeochromocytoma in pregnancy is rare. Untreated phaeochromocytoma has fatal consequences and carries a risk of mortality for the mother and the foetus, as high as $58 \%{ }^{6}$

The definitive treatment of phaeochromocytoma is surgical excision either open, laparoscopic or robotic approach. ${ }^{6}$ A brief literature review revealed that patients with phaeochromocytoma during pregnancy have been managed according to one of either. ${ }^{7,89}$ First approach is medical management up to the end of pregnancy and then tumour excision along with caesarean section. This approach is appropriate for patients who present late in pregnancy as in this case. The second approach is resection of phaeochromocytoma preferably during the second trimester.

As there is no current consensus on proper timing of surgery, the decision should be individualised and taken by a multidisciplinary team including obstetrician, endocrinologist and anaesthetist. Maintenance of uteroplacental circulation until the delivery and stable haemodynamics without wide fluctuations were our main targets of anaesthesia.

A $15^{0}$ left tilt was used to avoid aortocaval compression until delivery to improve uteroplacental circulation

Magnesium sulphate reduces catecholamine release from adrenal medulla and adrenergic nerve terminals and is useful to obtund intubation and extubation response and tumour handling ${ }^{\mathbf{1 0}}$ Remifentanil has a quick onset and is very effective in obtunding the intubation response.

Phentolamine is a reversible, non-selective $\alpha$ receptor antagonist that causes vasodilatation and reflex tachycardia. It is administered as a bolus of $1-2 \mathrm{mg}$ and has a short duration of action. 
Esmolol is a selective $\beta_{1}$ antagonist with a rapid action and short duration. It was used as an infusion to control the tachycardia.

Therefore, a combination of alpha blockade, general anaesthesia, magnesium infusion, remifentanil, esmolol and phentolamine were used to limit the hypertensive response and tachycardia and lead to a successful outcome for this patient who underwent caesarean section and adrenelectomy.

\section{References}

1. Pardo dos Santos DR, Barbisan CC, Marcellini C et al. Phaeochromocytoma and pregnancy: A case report and review: J Bras Nefrol 2015;37(4):496500

https://doi.org/10.5935/0101-2800.20150078

2. Connor D, Boumphrey S. Perioperative care of phaeochromocytoma.

3. BJA Education 2016:16(5):153-158 https://doi.org/10.1093/bjaed/mkv033

4. Chen H, Sippel RS, O'Dorisio MS, Vinik AI, Lloyd RV, Pacak K; North American Neuroendocrine Tumor Society (NANETS). The North American Neuroendocrine Tumor Society consensus guideline for the diagnosis and management of neuroendocrine tumors: pheochromocytoma, paraganglioma, and medullary thyroid cancer. Pancreas 2010;39:77583. PMID: 20664475

https://oi.org/10.1097/mpa.0b013e3181ebb4f0

5. Sarathi V, Bandgar TR, Menon PS, Shah NS. Pheochromocytoma and medullary thyroid carcinoma in a pregnant multiple endocrine neoplasia-2A patient. Gynecol Endocrinol 2011;27:533-5. doi.org/10.3109/09513590. 2010.507285

6. Lenders JW. Pheochromocytoma and pregnancy: a deceptive connection. Eur $J$ Endocrinol 2012;166:143-50. https://doi.org/10.1530/eje-11-0528

7. Oliva R, Angelos $\mathrm{P}$, Kaplan E, et al. Pheochromocytoma in pregnancy a case series and review. Hypertension 2010;55:600-6 https://doi.org/10.1161/hypertensionaha.109.147 579

8. Almog B, Kupferminc MJ, Many A, et al. Pheochromocytoma in pregnancy - a case report and review of the literature. Acta ObstetGynecolScand 2000;79:709-11

https://doi.org/10.1080/j.16000412.2000.079008709.x

9. Lowy C. Endocrine emergencies in pregnancy. Clin Endocrinol Metab 1980;9:569. https://doi.org/10.1210/eme.9781936704811.ch5

10. Leak D, Carroll J, Robinson D, et al. Management of pheochromocytoma during pregnancy. Can Med Assoc J 1977;116:371 https://doi.org/10.1097/00006254-19770900000005

11. Morton A, Poad D, Harms P, Lambley J. Phaeochromocytoma in pregnancy: timing of surgery, mode of delivery and magnesium. Obstetric Medicine 2010; 3: 164-5 https://doi.org/10.1258/om.2010.100033 